\title{
Atom Probe of Apatites - from Single Crystals to Interphases in Tooth Enamel
}

\author{
Lyle M. Gordon ${ }^{1}$, Karen A. Derocher ${ }^{1}$, Michael J. Cohen ${ }^{1}$, Derk Joester ${ }^{1}$. \\ ${ }^{1}$ Materials Science and Engineering, Northwestern University, Evanston, IL, USA.
}

Tooth enamel is the hardest tissue in vertebrates. Optimized to withstand the forces of mastication, it is composed of hydroxylapatite nanowires, thousands of which are bundled into rods that are organized in a three-dimensional weave. The outstanding fracture resistance of enamel and its long fatigue life are the consequence of this hierarchical architecture. Tooth enamel is also the target of the most prevalent infectious disease in humans: dental caries. It is an infectious disease that has extremely high morbidity, with $60-90 \%$ of children and nearly $100 \%$ of adults worldwide having or having had caries. ${ }^{[1]}$ Caries, simply put, is the destruction of tooth biominerals by dissolution and commonly begins with the demineralization of enamel by acids produced in plaque biofilms. It has long been known that the susceptibility of enamel to acid dissolution is greatly dependent on the presence of magnesium, carbonate, and fluoride ions. A major bottleneck in understanding formation, structural evolution, and degradation of enamel under normal conditions and during tooth decay has been that imaging the distribution of these impurities in enamel has remained a great challenge.

Others and we have recently shown that UV laser-pulsed atom-probe tomography (APT), in combination with correlative techniques, enables unprecedented insight into the nano-structure and chemistry of apatitic biominerals. ${ }^{[2-4]}$ This required developing a work flow for sample preparation, data collection, and data analysis tailored for apatites $\left(\mathrm{Ca}_{5}\left(\mathrm{PO}_{4}\right)_{3} \mathrm{X}, \mathrm{X}=\mathrm{F}, \mathrm{Cl}, \mathrm{OH}\right)$, wide band gap $(\sim 5.3 \mathrm{eV})$ insulators $^{[5]}$ that had never before been investigated by atom probe. We approached this by first performing a comprehensive analysis of synthetic and geologic single crystals of apatite end members. ${ }^{[2]}$ This was the basis for a second step, in which we analysed biogenic nanocomposites, including cortical bone and dentin. ${ }^{[2]}$ Our approach culminated in the recent discovery of amorphous interphases in tooth enamel and their importance in controlling mechanical properties and resistance to acid corrosion. ${ }^{[6,7]}$

We report here on the optimization of sample preparation conditions using FIB, the dependence of spectral quality and stoichiometry on atom probe operational parameters (Fig. 1), an analysis of multihit events in single-crystalline apatites (Fig. 2), and the differentiation of organic and inorganic carbon in enamel samples (Fig. 3). Finally, we will discuss preliminary results from atom probe of human enamel.

\section{References:}

[1] World Health Organization Media Centre, http://www.who.int/mediacentre/factsheets/fs318/en/.

[2] L. M. Gordon, L. Tran, D. Joester, ACS nano 6, (2012).

[3] J. Karlsson, G. Sundell, M. Thuvander, M. Andersson, Nano Letters 14, (2014).

[4] E. A. Marquis, M. Bachhav, Y. Chen, Y. Dong, L. M. Gordon, D. Joester, A. McFarland, Current Opinion in Solid State and Materials Science 17, (2014).

[5] P. Rulis, L. Ouyang, W. Y. Ching, Physical Review B 70, (2004).

[6] L. M. Gordon, D. Joester, Frontiers in Physiology 6, (2015).

[7] L. M. Gordon, M. J. Cohen, K. W. MacRenaris, J. D. Pasteris, T. Seda, D. Joester, Science 347 , (2015).

[9] The authors acknowledge funding from the National Science Foundation (NSF DMR-0805313, DMR-1106208, and DMR-1341391), the Northwestern University Materials Research Center (NSF- 
MRSEC DMR-1121262), the International Institute for Nanotechnology, the Institute for Sustainability and Energy at Northwestern (ISEN), the Petroleum Research Fund of the ACS. LMG was supported in part by the Canadian National Sciences and Engineering Research Council. MJC was supported in part by NIH predoctoral Biotechnology Training Grant T32GM008449.
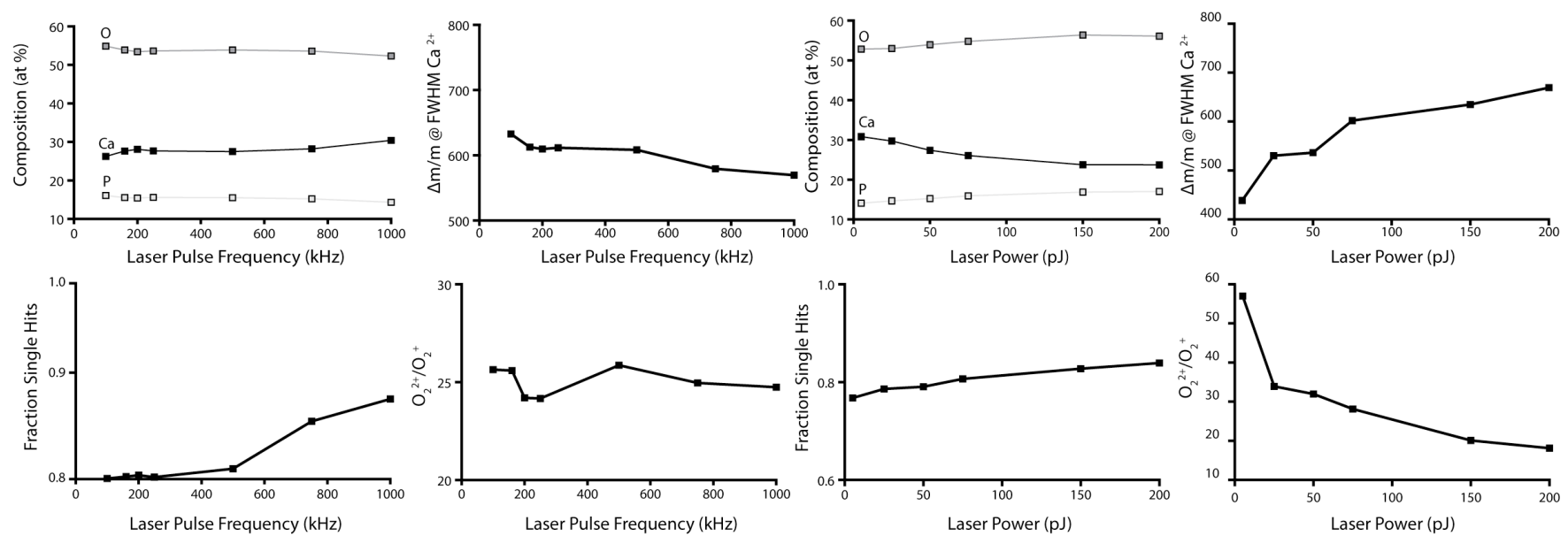

Figure 1. Optimization of stoichiometry $(A, C)$, mass resolving power $(B, D)$, single hit frequency $(E, G)$, and charge state ratio $(\mathrm{F}, \mathrm{H})$ as a function of laser pulse frequency $(\mathrm{A}, \mathrm{B}, \mathrm{E}, \mathrm{F})$ and laser power $(\mathrm{C}, \mathrm{D}, \mathrm{G}, \mathrm{H})$.
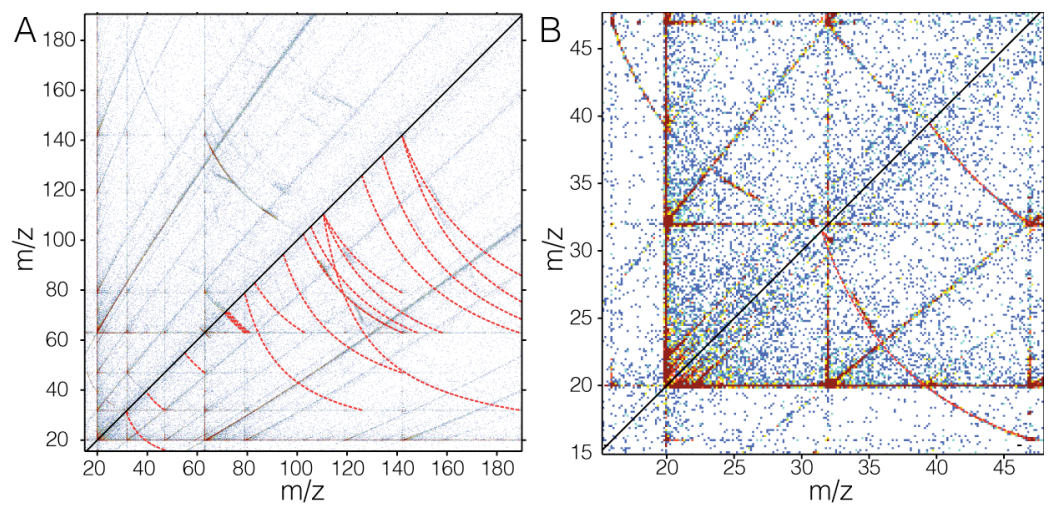

Figure 2. Double hit correlation histograms of a synthetic single crystal of hydroxylapatite. A. Correlation histogram with simulated decay tracks indicated below the diagonal (red arcs). B. Close up of (A), showing

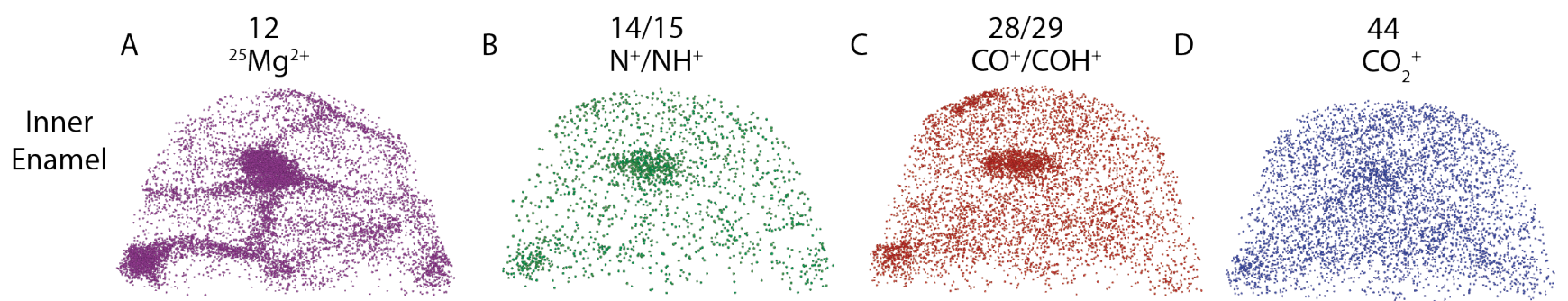

Figure 3. 3D Reconstructions of inner mouse enamel. A. Mg segregation at grain boundaries between hydroxylapatite nanowires. B. Nitrogen-containing ions in the intergranular precipitate. C,D. Carboncontaining ions originating from both organic and inorganic carbon. 